\title{
O DIREITO À COMUNICAÇÃO E A TUTELA DO MEIO AMBIENTE DIGITAL
}

\section{THE RIGHT TO COMMUNICATION AND PROTECTION OF THE ENVIRONMENT DIGITAL}

\author{
${ }^{1}$ Celso Antonio Pacheco Fiorillo \\ ${ }^{2}$ Carolina Ferreira Souza
}

\section{RESUMO}

O presente trabalho tem como objetivo investigar se existem instrumentos que garantam efetivamente o direito à comunicação social e sua tutela no meio ambiente digital, não apenas na internet, mas também em outros meios de comunicação, tendo em vista a já presente e cada vez maior convergência digital. O método utilizado foi o lógico dedutivo, a partir de análises de resenha de literatura específica, legislação e doutrina, partindo das premissas gerais da legislação existente sobre comunicação e meio ambiente cultural, para concluir que há necessidade de se regulamentar os artigos da $\mathrm{CF} / 88$ que tratam da comunicação social.

Palavras-chave: Direito à comunicação; Comunicação social; Meio ambiente digital; Meio ambiente cultural; Sociedade da informação.

\begin{abstract}
This study aims to investigate whether there are instruments that effectively guarantee the right to media and their protection in the middle of the digital environment, not only the Internet but also in other media, in view of the already present and growing convergence digital. The method used was deductive logic, from analysis review of the literature, legislation and doctrine, based on the general premises of existing legislation on communication and cultural environment, to conclude that there is need to regulate the articles of $\mathrm{CF} / 88$ dealing with the social communication.
\end{abstract}

Keywords: Right to communication; Social Communication; Digital environment; Cultural environment; Information society.

\footnotetext{
${ }^{1}$ Doutorado em Direito pela Pontifícia Universidade Católica - PUC, São Paulo, (Brasil). Professor Permanente do Programa de Mestrado em Direito da Universidade Nove de Julho - UNINOVE. Advogado militante há mais de 30 anos é Presidente da Comissão Permanente do Meio Ambiente da OAB/SP. E-mail: celsofiorillo@uol.com.br

2 Doutoranda em Direito das Relações Sociais (Direitos Difusos e Coletivos) pela Pontifícia Universidade Católica de São Paulo - PUC, São Paulo, (Brasil). Especialista em Direito do Consumidor pelo Instituição educacional, ESA-OAB/SP. E-mail: carolinafsouza@hotmail.com
} 


\section{INTRODUÇÃO}

O direito ambiental é um ramo do direito interdisciplinar por excelência, tendo em vista que tutela os bens ambientais essenciais à sadia qualidade de vida, conforme o caput do artigo 225, da Constituição Federal de 88:

Art. 225 Todos tem direito ao meio ambiente ecologicamente equilibrado, bem de uso comum do povo e essencial à sadia qualidade de vida, impondo-se ao Poder Público e à coletividade o dever de defendê-lo e preservá-lo para as presentes e futuras gerações.

O bem ambiental é todo "bem de uso comum do povo e essencial à sadia qualidade de vida", conceito indeterminado e aberto, sendo necessário preenchê-lo a fim de se compreender melhor a interdisciplinaridade do direito ambiental. São bens ambientais aqueles que garantam a dignidade da pessoa humana (art. 1º, III, CF) (FIORILLO, 2014). E os direitos sociais elencados no artigo $6^{\circ}$ da CF estabelecem um piso vital mínimo (FIORILLO, 2014), concretizando uma vida minimamente digna.

Desta feita, todos os bens necessários à efetivação da educação, da saúde, da alimentação, do trabalho, da moradia, do lazer, da segurança, da previdência social, da proteção à maternidade e à infância, e da assistência aos desamparados, são bens ambientais, de uso comum do povo.

Os bens ambientais podem ser estudados levando-se em consideração os diferentes aspectos do meio ambiente. As seis áreas mais expressivas do meio ambiente, segundo divisão de Celso Antonio Pacheco Fiorillo (2014, p. 71) são: meio ambientes natural, artificial, cultural, digital, do trabalho e do patrimônio genético.

Entende-se que a cultura de um povo, embora não esteja explicitamente elencada no rol do artigo $6^{\circ}$ da Constituição Federal, também é essencial a uma vida minimamente digna, na medida em que retrata os modos de viver de um determinado povo.

O presente trabalho estudará, portanto, dois dos aspectos do meio ambiente: o meio ambiente cultural e suas implicações no meio ambiente digital. O meio ambiente cultural é o aspecto do direito ambiental que estuda os bens de natureza material e imaterial, portadores de referência à identidade, à ação ou à memória dos diferentes grupos formadores da sociedade brasileira, como, por exemplo: as formas de expressão; os modos de criar, fazer e viver; as 
criações científicas, artísticas e tecnológicas; entre outros, conforme artigo 216 da Constituição Federal ${ }^{3}$.

As formas de acautelamento e preservação do patrimônio cultural brasileiro foram estabelecidas em uma época onde a rede mundial de computadores praticamente não existia. $\mathrm{Na}$ atual sociedade da informação, em que o armazenamento e a troca de informações se dá em larga escala através da rede mundial de computadores (internet), mister se faz o estudo da tutela do patrimônio cultural no ciberespaço, ou seja, do meio ambiente digital (FIORILLO, 2015).

A comunicação relaciona-se diretamente à tutela do meio ambiente cultural, tendo em vista que a divulgação, produção e reprodução do patrimônio cultural (tombado ou não) são muito mais eficientes quando transmitidos pelos meios de comunicação social, especialmente os meios de comunicação em massa.

A CF/88 incluiu o Capítulo V para tratar da comunicação social e, em seus artigos, estabeleceu alguns princípios a serem seguidos pela produção e programação do rádio e da televisão para que promovam a cultura em vários aspectos, e que serão abordados adiante.

O método utilizado foi o lógico dedutivo, a partir de análises de resenha de literatura específica, legislação e doutrina dos temas tratados, como comunicação, meio ambiente e meio ambiente digital.

O trabalho inicia-se com um estudo sobre o direito à comunicação, com um brevíssimo histórico do surgimento da comunicação, para, a seguir, pontuar as questões mais importantes sobre a comunicação social e, por fim, traçar os contornos de como se dá a tutela da cultura no meio ambiente digital na atual sociedade da informação.

\section{INÍCIO DA COMUNICAÇÃO HUMANA}

As primeiras referências sobre comunicação remetem aos tempos primórdios, quando os seres humanos primitivos começaram a associar determinado som ou gesto a certo objeto ou ação, nascendo, assim, o signo e a significação. O signo é qualquer coisa que faça referência a outra coisa ou ideia e a significação é o uso social dos signos e é exatamente a atribuição de

\footnotetext{
3 "Art. 216. Constituem patrimônio cultural brasileiro os bens de natureza material e imaterial, tomados individualmente ou em conjunto, portadores de referência à identidade, à ação, à memória dos diferentes grupos formadores da sociedade brasileira, nos quais se incluem: I - as formas de expressão; II - os modos de criar, fazer e viver; III - as criações científicas, artísticas e tecnológicas; IV - as obras, objetos, documentos, edificações e demais espaços destinados às manifestações artístico-culturais; $\mathrm{V}$ - os conjuntos urbanos e sítios de valor histórico, paisagístico, artístico, arqueológico, paleontológico, ecológico e científico".
} 
significados a determinados signos o que constitui a base da comunicação em geral e da linguagem em particular (DÍAZ BORDENAVE, 2006, p. 25).

Juan E. Díaz Bordenave ainda esclarece que com um significativo repertório de signos, os seres humanos primitivos criaram a gramática, ou seja, estabeleceram um conjunto de regrar para combinar signo e significado de modo padronizado para estender a comunicação a um número maior de pessoas. Com tais regras, foi criada a linguagem (2006, p. 25-26).

A maioria dos pesquisadores do tema concorda que se desenvolveu primeiro a linguagem oral, acompanhada ou não da linguagem gestual. Para fixar os signos e transmitilos, o ser humano utilizou primeiro o desenho e posteriormente a linguagem escrita. Foram encontrados desenhos em cavernas que remontam à era Paleolítica (entre 35000 e 15000 anos a.C.). Os hieróglifos do antigo Egito eram mais desenvolvidos, pois a imagem gráfica (desenho) correspondia exatamente com o objeto representado. É a chamada escrita pictográfica (DÍAZ BORDENAVE, 2006, p. 25-27). A escrita é um dos divisores de águas na História da humanidade; tanto que é justamente o marco entre o fim da Era Pré-Histórica e o início da Antiguidade.

Já na Antiguidade, os seres humanos perceberam que os signos gráficos poderiam representar unidades de som menores que as palavras (fonemas) e, a partir disso surgiram as letras, constituindo-se o alfabeto, onde cada letra representa um determinado som. Mesmo com os alfabetos, a cultura continuou sendo transmitida oralmente, pela linguagem falada, e visualmente, por meio das imagens. Durante a Idade Média, por exemplo, a linguagem escrita só era ensinada aos monges e a poucas pessoas da nobreza, mas os vitrais das catedrais contavam as histórias bíblicas. (DÍAZ BORDENAVE, 2006, p. 27-29).

Após esse brevíssimo resumo do início da comunicação da humanidade, percebe-se que, atualmente, ainda utilizamos, em todos os momentos de nossas vidas, as linguagens oral e escrita. Na escrita socorremo-nos das imagens (aliás, cada vez mais) e da escrita (cada povo com seu alfabeto). Essa constatação aparentemente banal demonstra o quanto a comunicação é inerente ao ser humano e, a partir disso, estudaremos algumas implicações do direito à comunicação.

\section{O DIREITO À COMUNICAÇÃO COMO UM DIREITO HUMANO}


Há que se considerar que no Brasil e em muitos outros países no mundo ainda encontramos uma importante parcela da população analfabeta. Existem os analfabetos absolutos e os analfabetos funcionais, que, embora conheçam o alfabeto e os algarismos, não conseguem interpretar um texto ou resolver uma operação matemática mais complexa. Recente pesquisa brasileira realizada pelo Instituto Paulo Montenegro e a ONG Ação Educativa aponta que $27 \%$ da população é analfabeta, sendo que $4 \%$ são analfabetos absolutos e $23 \%$ são analfabetos funcionais (INSTITUTO PAULO MONTENEGRO; AÇÃO EDUCATIVA, 2016).

Em relação à história da comunicação, o direito à comunicação é bem recente e guarda íntima relação com os direitos humanos, em especial com o direito à liberdade de expressão. A expressão "direito humano à comunicação" surge em 1969 no âmbito da Organização das Nações Unidas (ONU). A expressão foi cunhada pelo francês Jean D'arcy, então diretor de serviços audiovisuais e de rádio do Departamento de Informações Públicas das Nações Unidas, sendo por ele apresentada como um novo direito, que deveria ser garantido pelas normas internacionais (AGÊNCIA DE NOTÍCIAS DOS DIREITOS DA INFÂNCIA, [200-?]).

O direito à comunicação como direito humano e para além da liberdade de informação e de imprensa aparece também no Relatório MacBrid, de 1983, produzido pela Comissão Internacional para o Estudo dos Problemas da Comunicação, da Unesco. Uma das recomendações do relatório foi:

\footnotetext{
As necessidades de comunicação em uma sociedade democrática devem ser atendidas com a ampliação de direitos específicos, tais como o direito de informar e ser informado, o direito à privacidade, o direito de participação na comunicação pública - todos estes elementos de um novo conceito: o direito de comunicar-se. Ao desenvolvermos o que pode ser chamado de uma nova era de direitos sociais, sugerimos que todas as implicações do direito de comunicar-se sejam mais exploradas (UNESCO, 1983).
}

A defesa do direito humano à comunicação foi reforçada na Cúpula Mundial sobre a Sociedade da Informação realizada na ONU em dezembro de 2003, e contribuiu para o surgimento de uma campanha civil internacional intitulada Communications Rights in the Information Society (CRIS). Kofi Annan, secretário geral da ONU à época, declarou durante a Cúpula que "milhões de pessoas dos países mais pobres continuam excluídos do direito de comunicar-se, um direito cada vez mais percebido como um direito humano fundamental". (INTERVOZES, [200-?]).

Apesar dessas indicações, até o presente momento, a Unesco e a ONU ainda não previram em nenhuma resolução, tratado ou convenção o direito à comunicação como um 
direito humano. Até mesmo porque o tema foi menos debatido na Unesco e passou a ser tratado pela sociedade civil a partir da década de 90 (ALEGRE; O'SIOCHRU, [200-?]).

Diferentemente do entendimento de Jean D'arcy de que o direito humano à comunicação é um novo direito, uma atual corrente defende as expressões "direito humano à comunicação" ou "direito humano a comunicar-se" não como sendo um novo direito e sim:

[...] um termo de amplo espectro, englobando um grupo de direitos existentes e relacionados. Isso significa que qualquer elaboração do direito de comunicar-se deve acontecer dentro da estrutura dos direitos já existentes (Artigo 19 apud ALEGRE; O'SIOCHRU, [200-?]).

O Coletivo Intervozes também entende de forma similar:

[...] Embora alguns autores qualifiquem o direito humano à comunicação como "direito de acesso" ao espaço público, julga-se que a melhor forma de definir o direito humano à comunicação seja qualificá-lo como o direito à participação, em condições de igualdade formal e material, na esfera pública mediada pelas comunicações sociais e eletrônicas (grifo do autor) (INTERVOZES, [200-?]).

Dentre os direitos já existentes mencionados pelo Artigo 19, que englobam o "direito humano a comunicar-se", um deles foi explicitado pelo Coletivo Intervozes, que é "direito à participação, em condições de igualdade formal e material, na esfera pública mediada pelas comunicações sociais e eletrônicas”. Tal direito à participação é bastante amplo e pode ser considerado em diversos aspectos.

\section{O DIREITO HUMANO A COMUNICAR-SE E O DIREITO À PARTICIPAÇÃO}

O primeiro dos aspectos da participação é o já mais do que consagrado direito à liberdade de expressão. A Declaração Universal dos Direitos Humanos, de 1948 garante expressamente as liberdades de opinião e de expressão em seu artigo XIX, in verbis:

Art. XIX. Toda pessoa tem direito à liberdade de opinião e expressão; este direito inclui a liberdade de, sem interferência, ter opiniões e de procurar, receber e transmitir informações e idéias por quaisquer meios e independentemente de fronteiras. 
O Pacto Internacional dos Direitos Civis e Políticos, aprovado em 1966, com entrada em vigor em 1976 e aprovado pelo Brasil em 1992, também tem previsão muito similiar, in verbis:

Art. 19. Toda pessoa terá direito à liberdade de expressão; esse direito incluirá a liberdade de procurar, receber e difundir informações e idéias de qualquer natureza, independentemente de considerações de fronteiras, verbalmente ou por escrito, em forma impressa ou artística, ou qualquer outro meio de sua escolha.

Não foi diferente na Convenção Americana de Direitos Humanos, conhecida como Pacto de San Jose da Costa Rica, de 1969, da qual o Brasil é signatário, no art. 13:

Art. 13.

1. Toda pessoa tem direito à liberdade de pensamento e de expressão. Esse direito compreende a liberdade de buscar, receber e difundir informações e ideias de toda natureza, sem consideração de fronteiras, verbalmente ou por escrito, ou em forma impressa ou artística, ou por qualquer outro processo de sua escolha [...].

O direito à liberdade de expressão foi se ampliando desde suas concepções iniciais, para abarcar também o direito à informação, que compreende o direito de cada indivíduo de informar, informar-se e ser informado, bem como a liberdade de imprensa, que pode ser resumida como a liberdade de afirmar, escrever, documentar e veicular todas as informações de interesse público (INTERVOZES, [200-?]).

Mesmo com esse conceito mais ampliado, há algumas décadas vem sendo questionado e ainda questiona-se se ele é suficiente para atender as reais demandas da sociedade e, mais recentemente, da sociedade da informação:

O século XXI caracteriza-se pelo que se define como "sociedade da informação", em que as tecnologias da comunicação fornecem a base material para a integração global e favorecem o intercâmbio cada vez mais veloz de informações entre indivíduos, corporações e instituições. Apesar das contradições e desigualdades que se fazem presentes neste contexto, a sociedade da informação caracteriza nova forma de produção de relações sociais, baseada na flexibilidade e no incentivo à capacidade criacional (FIORILLO, 2010).

Exatamente por causa das contradições e desigualdades na atual sociedade da informação é que se discute se a liberdade de expressão é suficiente para garantir essa nova 
conformação do direito de comunicar-se e mesmo se existe real liberdade de expressão para todos. Neste sentido, ponderam Alan Alegre e Sean O'Siochru:

\begin{abstract}
O ideal do qual a liberdade de expressão retira sua legitimidade considera um grupo de indivíduos em processo de comunicação, cada um com igual direito de conceber, partilhar e receber idéias de outros e, assim, chegar racionalmente às decisões para o benefício mútuo. O problema é que não vivemos como um grupo de indivíduos com os mesmos poderes. Vivemos em uma sociedade com enormes variações nos níveis de acesso ao poder, uma sociedade na qual a maior parte da comunicação entre as pessoas é fortemente mediada e filtrada - por mídia em massa, governos, corporações comerciais, grupos de interesses especiais e muitos outros - todos competindo por atenção, procurando influenciar e controlar o conteúdo e o fluxo das comunicações. Insistir apenas na liberdade de expressão em nada afetará o processo pelo qual os meios de expressão da sociedade - jornais, televisão, rádio, filmes, música e materiais didáticos - são controlados e em que interesses eles operam (ALEGRE; O'SIOCHRU, [200-?]).
\end{abstract}

Nota-se que a avaliação acima contempla o outro aspecto essencial e que apresenta uma das contradições importantes na sociedade da informação: apesar do grande fluxo de informações entre os diferentes povos e culturas permitido pela comunicação digital, em especial pela rede mundial de computadores, ainda é incipiente a participação das minorias na produção do conteúdo difundido de forma massiva.

É certo que são registrados avanços importantes. Muito conteúdo produzido e divulgado por esses grupos minoritários (como, por exemplo, indígenas, quilombolas, mulheres, grupos $\mathrm{LGBT}^{4}$ etc) está à disposição para consulta em páginas na internet. Todavia, sabe-se que estamos longe de que esses e outros conteúdos imprescindíveis para o desenvolvimento humano atinjam todos os indivíduos.

\title{
3.1 A comunicação social em um Estado Democrático de Direito
}

Em um Estado Democrático de Direito a comunicação de massa tem papel fundamental, especialmente em um país com tamanha desigualdade social como o Brasil. Dados do mais recente relatório do Programa das Nações Unidas para o Desenvolvimento (PNUD), o Relatório do Desenvolvimento Humano 2015, "O trabalho como motor do desenvolvimento humano" elenca o Brasil na $75^{a}$ colocação no ranking mundial do Índice de Desenvolvimento Humano (IDH), bem como na $13^{\mathrm{a}}$ colocação na América Latina, atrás de

\footnotetext{
${ }^{4}$ Lésbicas, Gays, Bissexuais e Transgêneros (como, por exemplo, Travestis e Transexuais).
} 
diversos países como Venezuela, Cuba, Uruguai, Chile e Argentina (PROGRAMA DAS NAÇÕES UNIDAS PARA O DESENVOLVIMENTO, 2015).

Acerca da função da comunicação social, Díaz Bordenave traz as seguintes considerações:

\begin{abstract}
E a comunicação? Será que o modo de nossa sociedade usar sua comunicação "social" responde às necessidades das pessoas reais? Os meios de comunicação ajudam na tomada de decisões importantes? Oferecem oportunidades de expressão a todos os setores da população? Fornecem ocasiões de diálogo e de encontro? Estimulam o crescimento da consciência crítica e da capacidade de participação? Questionam os regimes políticos e as estruturas sociais que não respondem aos anseios de liberdade, convívio, beleza, além de não satisfazer às necessidades básicas da população?

Os meios de comunicação, organizados e manejados segundo modelos forâneos verticais e unilaterais, a não ser raras exceções, parecem procurar mais o lucro, o prestígio, o poder e o domínio do que a construção de uma sociedade participativa, igualitária e solidária, onde as pessoas realizem plenamente seu potencial humano (DÍAZ BORDENAVE, 2006, p. 9).
\end{abstract}

Significativa parte dos brasileiros ainda informa-se pela televisão, como vem mostrando algumas pesquisas. A mais recente delas, realizada pela Secretaria de Comunicação (Secom), a Pesquisa Brasileira de Mídia - PBM 2015 apresenta dados interessantes. 73\% dos brasileiros afirmam assistir televisão todos os dias e dentre todos aqueles que assistem televisão, $79 \%$ o fazem para se informar e $4 \%$ para estudar ou aprender. (SECRETARIA DE COMUNICAÇÃO SOCIAL, 2014). Portanto, apesar do crescimento vertiginoso da rede mundial de computadores, a televisão ainda deve ser objeto de debate no campo da comunicação social.

Se grande parte dos brasileiros assiste televisão para se informar, é de se questionar quais e como tais informações são transmitidas. Pois, caso fossem apresentadas de forma a cumprir os objetivos da comunicação elencados acima por Díaz Bordenave, como, por exemplo, o de ajudar na tomada de decisões importantes, o Brasil possivelmente não estaria em $75^{\mathrm{a}}$ colocação no ranking mundial do Índice de Desenvolvimento Humano - IDH.

Certamente que apenas transmissão de informações adequadas não é suficiente para o desenvolvimento de um povo; é necessário saber o que fazer com elas, interpretá-las e aplicálas corretamente. E esse é um dos outros objetivos da comunicação social mencionado por Díaz Bordenave, pois ela deve estimular o crescimento da consciência crítica e da capacidade de participação.

Outro aspecto essencial acerca da definição do direito à comunicar-se trazido pelo Coletivo Intervozes, qual seja, "o direito à participação, em condições de igualdade formal e 
material, na esfera pública mediada pelas comunicações sociais e eletrônicas", é o da participação social nos processos de decisão, produção e veiculação dos conteúdos divulgados pelas mídias.

O capítulo que trata da Comunicação Social na Constituição Federal, como mencionado na introdução, é o Capítulo V, do artigo 220 ao 224. O parágrafo segundo do artigo 220 esclarece: " $\S 2^{\circ}$ É vedada toda e qualquer censura de natureza política, ideológica e artística". E o que propõe a maioria dos movimentos sociais e movimentos civis organizados é bastante diferente de censura e tem fundamento na própria Constituição de 88 .

O artigo 224, por exemplo, determinou a criação do Conselho de Comunicação Social, o que foi atendido em 1991, pela Lei n. 8.389/91. Todavia, foi uma criação meramente formal, sendo que apenas em 2002 teve a primeira indicação de nomes para sua composição e teve seu funcionamento interrompido em 2004, somente tendo sido retomado em 2012 (AGÊNCIA CÂMARA DE NOTÍCIAS, 2012).

Desde então, a própria indicação dos nomes vem sendo contestada por movimentos ligados à defesa de uma comunicação social mais democrática, como, por exemplo, o Fórum Nacional pela Democratização da Comunicação - FNDC (FÓRUM NACIONAL PELA DEMOCRATIZAÇÃO DA COMUNICAÇÃO, 2012). Os movimentos sociais e movimentos civis organizados reclamam que os nomes dos representantes da sociedade civil não são por ela indicados, mas escolhidos e nomeados pelo Congresso Nacional sem ao menos consultar a população.

Mais recentes foram as polêmicas indicações de pessoas ligadas ao próprio Estado, como, por exemplo, o à época Ministro do Turismo, Henrique Eduardo Alves em 2015 (MELO, 2015).

Outro elemento que dificulta ainda mais a participação direta da população em temas ligados à comunicação é que o próprio Conselho de Comunicação Social é apenas consultivo. O $\operatorname{artigo} 2^{\circ}$ da Lei 8.389/91 é bem explícito ao definir a atribuição do Conselho:

Art. $2^{\circ}$ O Conselho de Comunicação Social terá como atribuição a realização de estudos, pareceres, recomendações e outras solicitações que lhe forem encaminhadas pelo Congresso Nacional a respeito do Título VIII, Capítulo V, da Constituição Federal, em especial sobre: [...].

Em nenhum outro dispositivo da mencionada Lei encontra-se alguma menção a possíveis deliberações nos temas de comunicação social levados ao Conselho, embora durantes 
as discussões na Assembleia Nacional Constituinte, a Federação Nacional dos Jornalistas (Fenaj) e a Frente Nacional por Políticas Democráticas de Comunicação tivessem defendido que: “[...] O Conselho Nacional de Comunicação deve ser o órgão encarregado de elaborar as políticas para o setor e de fazer as concessões para a exploração dos serviços;" (JAMBEIRO, 2001, p. 146).

Bastante esclarecedoras são as considerações de Othon Jambeiro:

\begin{abstract}
Durante a Assembléia Constituinte dois grandes grupos polarizaram o debate sobre os dispositivos que regulamentariam a exploração dos serviços de TV: (1) a Fenaj Federação Nacional dos Jornalistas, aliada aos parlamentares tidos como progressistas; (2) a Abert - Associação Brasileira das Emissoras de Rádio e Televisão, aliada aos parlamentares pertencentes ao que se convencionou chamar de 'centrão' . A Abert defendia que a radiodifusão deveria ser controlada pelo Poder Executivo e explorada pela iniciativa privada. Ou seja, queria a manutenção do modelo introduzido pelo Código Nacional de Telecomunicações e a permanência dos princípios básicos da Regulamentação dos Serviços de Radiodifusão. Ao contrário da Abert, a Fenaj propunha a criação de um Conselho Nacional de Comunicação para regular o rádio e a televisão. O Conselho seria um órgão coletivo autônomo, com atribuições executivas, e composto, na sua maioria, por representantes de entidades de trabalhadores e da sociedade civil. A exploração dos serviços de rádio e TV deveria ser feita por fundações sem fins lucrativos (2000, p. 82-83).
\end{abstract}

Os interesses das grandes corporações de comunicação e do entretenimento prevaleceram em grande parte e nenhuma participação direta da sociedade foi autorizada nas tomadas de decisão na área da comunicação social. A atual percepção dos movimentos atuantes de que o "direito humano à comunicação" ou "direito humano a comunicar-se" depende dessa participação mais democrática e direta em todo o processo de produção de conteúdos midiáticos está muito longe de ser alcançada no Brasil.

O artigo 221 da Lei Maior, que estabelece princípios para a produção e programação de emissoras de rádio e televisão, ainda não foi regulamentado. Estabelece o dispositivo:

Art. 221. A produção e a programação das emissoras de rádio e televisão atenderão aos seguintes princípios:

I - preferência a finalidades educativas, artísticas, culturais e informativas;

II - promoção da cultura nacional e regional e estímulo à produção independente que objetive sua divulgação;

III - regionalização da produção cultural, artística e jornalística, conforme percentuais estabelecidos em lei;

IV - respeito aos valores éticos e sociais da pessoa e da família.

\footnotetext{
${ }^{5}$ Deu-se o nome de Centrão ao conjunto de parlamentares situados do centro para a direita no espectro ideológico da Constituinte, a eles agregados os vinculados às religiões e aqueles que usam o mandato para obter vantagens pessoais, como concessões de rádio e TV, por exemplo (nota do autor).
} 
Nota-se no artigo 221 a reafirmação da própria Constituição Federal da intrínseca relação entre comunicação social e cultura, inserindo a proteção da produção cultural (bem como de outros elementos) como princípio.

A reivindicação dos movimentos que lutam por uma maior democratização da mídia, em especial por maior participação nos processos de decisão, produção e divulgação dos conteúdos artísticos, culturais e jornalísticos poderá ser atendido se houver a regulação de alguns artigos da Constituição Federal, como o supra transcrito artigo 221.

Em tramitação há alguns anos, um Projeto de Lei (PL), de autoria da Comissão Mista propõe a regulamentação de dispositivos da Constituição Federal, o PL n. 5.992/2013, definindo justamente o tempo da programação diária das emissoras de rádio e televisão que deverá ser ocupado pela programação regional, e traz elementos para a conceituação de produção independente, tendo em vista o disposto no supra transcrito artigo 221, II e III, CF.

O projeto define produção de caráter regional como sendo a produção cultural, artística e jornalística produzida na região do País onde está localizada a emissora (Norte, Nordeste, Centro-Oeste, Sudeste ou Sul) e a produção local aquela que é realizada no estado (unidade federativa) da emissora. Outro elemento importante é caracterização de produção independente regional como sendo a desenvolvida por outra empresa localizada na região, que tenha atividade regular e não seja vinculada societariamente, direta ou indiretamente, à emissora.

A produção deverá ser dividida igualmente entre regional e local e respeitar os seguintes valores mínimos semanais:
a) localidades com até 500 mil habitantes: 336 minutos;
b) localidades entre 500 mil e 1 milhão de habitantes: 504 minutos;
c) municípios com população entre 1 milhão e 5 milhões de habitantes: 616 minutos;
d) locais com população superior a 5 milhões de habitantes: 840 minutos.

Seria um avanço tal regulamentação, no entanto, essa cota mínima ainda é pequena perto da totalidade da programação, pois a programação semanal soma 10.080 minutos. Nos locais com população superior a cinco milhões de habitantes, faixa onde a cota seria de 840 minutos, isto representa pouco mais de $8 \%$ do total da programação. 
Outras questões podem ser levantadas nessa regulamentação para a efetiva diversidade de programação, como, por exemplo, se as emissoras teriam liberdade para transmitir tal conteúdo em qualquer horário. Para cumprir a determinação legal, poderiam transmitir a programação regional de madrugada, sem que a divulgação para um grande número de telespectadores ou ouvintes seja efetivada.

Não há também neste PL qualquer menção à participação direta da sociedade civil na produção dos conteúdos, elemento central das reivindicações dos movimentos civis organizados. É importante destacar também que o PL apenas trata da regulamentação nos meios de comunicação tradicionais: o rádio e a televisão. Algumas considerações sobre a tutela da comunicação social no ambiente digital serão expostas a seguir.

\section{A COMUNICAÇÃO SOCIAL NO MEIO AMBIENTE DIGITAL}

A partir das considerações de Celso Antonio Pacheco Fiorillo, é possível conceituar meio ambiente digital como o ramo do Direito Ambiental que estuda os bens portadores de referência à identidade, à ação e à memória dos grupos formadores da sociedade brasileira no meio digital, incluindo a rede mundial de computadores (internet) (2014).

Deste modo, é importante apontar se o arcabouço legal que regulamenta a comunicação social nos meios de comunicação tradicionais, como o rádio e a televisão, é aplicável ao meio digital. De plano, é possível afirmar que sim, tendo em vista que antes mesmo de se analisar os dispositivos específicos acerca da comunicação social, uma série de outros fundamentos e princípios constitucionais atingem todas as relações jurídicas que acontecem em solo brasileiro.

Assim, o artigo $1^{\circ}$, CF que traz os fundamentos da República Federativa do Brasil e entre eles o mais importante, que é a dignidade da pessoa humana no inciso III, bem como o artigo $3^{\circ}, \mathrm{CF}$ que elenca os objetivos brasileiros, além do artigo $5^{\circ}$ que enumera dezenas de direitos individuais e coletivos, apenas para apontar os mais significativos, são todos aplicáveis à tutela da comunicação social no meio ambiente digital.

Especificamente em relação ao Capítulo V da Constituição Federal que trata da Comunicação Social é pertinente observar que em diversos artigos são utilizados termos genéricos, como "qualquer veículo de comunicação social” (art. 220, §1ºu ou "meios de 
comunicação social" (art. 220, $\S 5^{\circ}$ ). Desta feita, certamente também abarcam os meios de comunicação social digital.

Em relação aos dispositivos que mencionam diretamente "emissoras de rádio e televisão", como o artigo 221, a Emenda Constitucional (EC) n 36 de 2002 esclarece que os elementos do mencionado artigo 221 também devem ser respeitados pelos meios eletrônicos, determinando no artigo $222, \S 3^{\circ}$ que:

Art. 222 [...] $\S 3^{\circ}$ Os meios de comunicação social eletrônica, independentemente da tecnologia utilizada para a prestação do serviço, deverão observar os princípios enunciados no art. 221, na forma de lei específica, que também garantirá a prioridade de profissionais brasileiros na execução de produções nacionais.

Tal previsão vem ao encontro do fenômeno cada vez mais crescente na comunicação social: a convergência das mídias, onde as plataformas de televisão, rádio, rede mundial de computadores (internet), videogames, tablets e telefones fixo e celular, interligam-se cada vez mais. E apesar de termos legislações específicas para cada setor, como a Lei Geral das Telecomunicações (Lei n. 9.472/97) ou o Marco Civil da Internet (Lei n. 12.965/2014), a Constituição Federal deve ser obedecida em primeiro lugar.

A comunicação social é um direito difuso, ou seja, transindividual, de natureza indivisível, cujos titulares são pessoas indeterminadas e ligadas por circunstâncias de fato (art. 81, parágrafo único, I da Lei n. 8.078/90, o Código de Defesa do Consumidor) e as empresas privadas que atuam nessa área devem ter ciência de suas responsabilidades na formação de cidadãos e cidadãs brasileiros.

As cotas nas programações previstas no PL n. 5.992/2003 e que também deverão ser aplicadas às programações veiculadas pelos meios eletrônicos, como a internet já são um avanço, mas ainda não atendem às expectativas dos movimentos sociais e civis organizados que atuam nessa área da comunicação de participação efetiva e direta na produção dos conteúdos.

$\mathrm{O}$ próprio PL supra citado, em seu artigo $6^{\circ}$ traz uma possibilidade para essa participação direta. Estabelece que:

$\mathrm{O}$ art. $4^{\circ}$ da Lei $\mathrm{n}^{\mathrm{o}} 8.313$, de 23 de dezembro de 1991, passa a vigorar acrescido do seguinte $\S 9^{\circ}$ :

"Art. $4^{\circ}$

$\S 9^{\circ}$ No mínimo $5 \%$ dos recursos do Fundo Nacional de Cultura serão destinados à regionalização da produção cultural, artística e jornalística das empresas de radiodifusão sonora e de sons e imagens". 
A Lei no 8.313 de 1991 é a que instituiu o Programa Nacional de Apoio à Cultura (Pronac). E o mencionado Fundo Nacional de Cultura é constituído com recursos do Tesouro Nacional, doações e auxílios de entidades nacionais ou estrangeiras (art. $5^{\circ}$ da Lei $n^{\circ}$ 8.313/91). Como o Fundo é mantido também com recursos públicos, uma maior participação da sociedade civil parece ser possível.

Conjugado com outro dispositivo da Constituição Federal, uma interpretação sistemática de comunicação e cultura autorizando a participação direta da produção e divulgação de conteúdos que protejam as formas de expressão, os modos de criar, fazer e viver, as criações científicas, artísticas e tecnológicas, as obras, objetos, documentos, edificações e demais espaços destinados às manifestações artístico culturais dos grupos formadores da sociedade brasileira (art. 216, CF) é bastante plausível.

O artigo 216-A da Constituição Brasileira, inserido pela Emenda n. 71/2012, criou o Sistema Nacional de Cultura, e elegeu como princípio, dentre outros, a democratização dos processos decisórios com participação e controle social, conforme dispõe o artigo 216-A, $\S 1^{\circ}$, $\mathrm{X}$ da $\mathrm{CF}$, in verbis:

\footnotetext{
"Art. 216-A. O Sistema Nacional de Cultura, organizado em regime de colaboração, de forma descentralizada e participativa, institui um processo de gestão e promoção conjunta de políticas públicas de cultura, democráticas e permanentes, pactuadas entre os entes da Federação e a sociedade, tendo por objetivo promover o desenvolvimento humano, social e econômico com pleno exercício dos direitos culturais.

$\S 1^{\circ} \mathrm{O}$ Sistema Nacional de Cultura fundamenta-se na política nacional de cultura e nas suas diretrizes, estabelecidas no Plano Nacional de Cultura, e rege-se pelos seguintes princípios:

$[\ldots]$

$\mathrm{X}$ - democratização dos processos decisórios com participação e controle social; (grifo nosso)".
}

Tal dispositivo permite que haja participação social direta para decidir qual conteúdo poderá ser ou não objeto do Plano Nacional de Cultura e, portanto, financiados pelo Ministério da Cultura. No mesmo artigo 216-A, mas em seu $\S 2^{\circ}$, II prevê onde pode se dar tal participação e controle social:

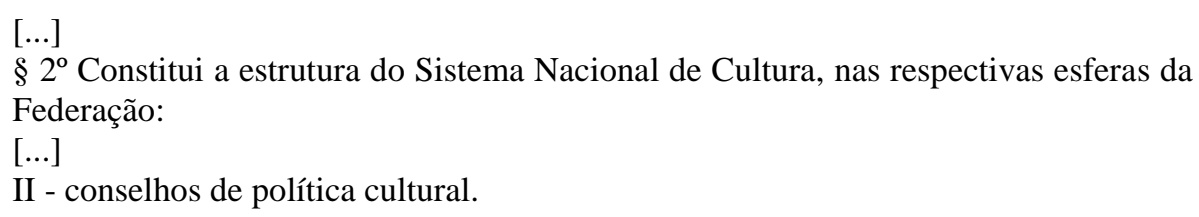


Esclarece o documento elaborado pelo Ministério da Cultura:

Os Conselhos de Política Cultural são instâncias colegiadas permanentes, de caráter consultivo e deliberativo, integrantes da estrutura básica do órgão da Administração Pública responsável pela política cultural, em cada esfera de governo, tendo na sua composição, no mínimo, 50\% de representantes da Sociedade Civil, eleitos democraticamente, conforme deliberado na I Conferência Nacional de Cultura e no Plenário do Conselho Nacional de Política Cultural, relativo à proposta do Plano Nacional de Cultura. Sua principal finalidade é atuar na formulação de estratégias e no controle da execução das políticas públicas de Cultura (grifo nosso) (MINISTÉRIO DA CULTURA, 2011).

Percebe-se uma expressiva representatividade da sociedade civil nesses Conselhos que atuarão nas esferas Federal, Estadual e Municipal de, no mínimo, 50\% de seus membros. Além disso, destaque-se que há previsão expressa de deliberação dos Conselhos no que tange as políticas culturais, ou seja, a tão almejada participação direta nas decisões.

O referido controle social, muito diferente de censura, é a participação democrática da sociedade em todas as etapas de atuação da administração pública ou privada que envolvam direitos da coletividade. E quando se trata da tutela de direitos humanos tão importantes como o direito a comunicar-se e o direito à cultura a participação direta da sociedade deve se fazer presente.

\section{CONSIDERAÇÕES FINAIS}

A comunicação é inerente ao ser humano, seja ela escrita, falada ou gestual. No entanto, a proteção à esse direito vem ganhando contornos diferentes a partir do século XX, quando dois aspectos do direito à comunicação foram assegurados como direitos humanos na Declaração Universal dos Direitos Humanos, de 1948, quais sejam: o direito à liberdade de opinião e o direito à liberdade de expressão.

No final da década de 1960, Jean D'arcy, membro da ONU à época, apresenta a expressão “direito humano à comunicação" e o Relatório MacBrid, de 1983, da Unesco defende a expressão "direito humano de comunicar-se”, para além dos já assegurados (ao menos formalmente) direitos à liberdade de expressão, de opinião e de imprensa, incluindo os direitos de informar, ser informado e informar-se, o direito à privacidade, o direito de participação na comunicação pública.

Para poder expressar-se ou opinar livremente, é necessário que o cidadão tenha efetivamente seus direitos de informar, ser informado e informar-se amplamente garantidos. $\mathrm{E}$ 
tais informações devem ser tais ou com tal qualidade que garantam a tomada de decisões de forma consciente.

Como consta do mencionado Relatório MacBrid, com o surgimento de uma nova era de direitos sociais, as implicações do direito de comunicar-se devem ser mais exploradas, em especial o direito à participação. E como o tema foi perdendo destaque nas discussões na Unesco, a sociedade civil passou a organizar-se para debatê-lo.

Questão essencial que cerca a temática é um dos temas que se pretendeu abordar no presente trabalho: a tutela do meio ambiente digital na sociedade da informação. Para que a comunicação difundida pelos meios de comunicação de massa seja realmente democrática, há que se veicular conteúdos culturais nacionais e regionais, estimulando a produção independente, desvinculada das grandes corporações midiáticas.

A legislação constitucional brasileira é bastante clara quando elenca os princípios a serem seguidos pelas emissoras de rádio e televisão quanto ao conteúdo que deve preferencialmente ser veiculado, coroando no artigo 221, CF a tutela do patrimônio cultural brasileiro na comunicação social.

Todavia, tais princípios, que também são aplicáveis aos meios de comunicação social eletrônica por força expressa da EC n. 36/2002, que inseriu tal extensão no $\S 3^{\circ}$ do artigo 222 , $\mathrm{CF}$, ainda não foram regulamentados. Destarte, o patrimônio cultural brasileiro não vem sendo protegido e divulgado conforme mandamento constitucional.

E a partir do novo entendimento do direito à comunicação como um direito humano de comunicar-se, com participação ativa dos cidadãos e cidadãs nos processos comunicacionais, os movimentos sociais e movimentos civis organizados eles têm cobrado maior inserção da sociedade civil nos processos decisórios.

Desta forma, é essencial a regulamentação de alguns artigos que tratam da comunicação social, em especial o artigo que mais foi abordado no presente trabalho, que é o artigo 221, CF.

O PL n. 5.992/2003, que tramita há 13 anos no Congresso Nacional, propõe soluções interessantes, como as cotas das programações regional e local e a utilização do Fundo Nacional de Cultura para financiar tais produções artísticas, culturais e jornalísticas regionais. E o artigo 216-A, $\S 1^{\circ}, \mathrm{X}, \mathrm{CF}$, elencou como princípio do Sistema Nacional de Cultura, "a democratização dos processos decisórios com participação e controle social". 
A legislação constitucional, portanto, previu e autorizou uma atuação da sociedade civil nos processos decisórios através de controle social na proteção da cultura nacional, através, principalmente dos Conselhos de Política Cultural. Desta forma, se o PL n. 5.992/2003 for aprovado trará uma maior possibilidade de participação direta na escolha do conteúdo regional a ser financiado pelo Fundo Nacional de Cultura, atendendo, ao menos em parte, os anseios e as reivindicações dos movimentos ligados à comunicação.

\section{REFERÊNCIAS BIBLIOGRÁFICAS}

\section{AGÊNCIA CÂMARA DE NOTÍCIAS. Conselho de Comunicação Social é empossado no}

\section{Congresso.}

08.08.2012.

Disponível

em

$<$ http://www2.camara.leg.br/camaranoticias/noticias/COMUNICACAO/423761-CONSELHO-DECOMUNICACAO-SOCIAL-E-EMPOSSADO-NO-CONGRESSO.html>. Acesso em 22.06.2016.

AGÊNCIA DE NOTÍCIAS DOS DIREITOS DA INFÂNCIA (ANDI). Cenário internacional. [200-?] Disponível em <http://www.andi.org.br/politicas-decomunicacao/page/cenario-internacional>. Acesso em 20.06.2016.

ALEGRE, Alan; O'SIOCHRU, Sean. Direitos da comunicação. In: Desafio de palavras: enfoques multiculturais sobre as sociedades da informação. [200-?] Disponível em <http://vecam.org/archives/article672.html>. Acesso em 15.05.2016.

BRASIL. CÂMARA DOS DEPUTADOS. Projeto de Lei 5.992/2013. Regulamenta o disposto no inciso III do art. 221 da Constituição Federal, para estabelecer percentuais de regionalização de produção cultural, artística e jornalística das emissoras de radiodifusão sonora e de sons e imagens. Disponível em <http://www.camara.gov.br/proposicoesWeb/prop_mostrarintegra;jsessionid=7182700178A49EA0F5 8C522001319839.proposicoesWeb1?codteor=1110733\&filename=PL+5992/2013> . Acesso 01.09.2016.

. Constituição (1988). Constituição da República Federativa do Brasil. Brasília, DF: Senado, 1988. 
Constituição (1988). Emenda constitucional n. ${ }^{0}$ 36, de 28 de maio de 2002. Disponível em <http://www.planalto.gov.br/ccivil_03/constituicao/emendas/emc/emc36.htm>. Acesso em 05.06.2016.

Constituição (1988). Emenda constitucional n. ${ }^{\circ} 71$, de 29 de novembro de 2012. Disponível em <http://www.planalto.gov.br/ccivil_03/constituicao/Emendas/Emc/emc71.htm>. Acesso em 05.06.2016.

Decreto n. ${ }^{\circ}$ 592, de 6 de julho de 1992. Atos Internacionais. Pacto Internacional sobre Direitos Civis e Políticos. Promulgação. Disponível em <http://www.planalto.gov.br/ccivil_03/decreto/1990-1994/d0592.htm>. Acesso em 02.05.2016.

Decreto n. ${ }^{0}$ 678, de 6 de novembro de 1992. Promulga a Convenção Americana sobre Direitos Humanos (Pacto de São José da Costa Rica), de 22 de novembro de 1969. Disponível em <http://www.planalto.gov.br/ccivil_03/decreto/D0678.htm>. Acesso em 02.05.2016.

Lei n. ${ }^{\circ}$ 8.078, de 11 de setembro de 1990. Disponível em <http://www.planalto.gov.br/ccivil_03/leis/18078.htm>. Acesso em 01.05.2016.

Lei n. ${ }^{\circ}$ 8.313, de 23 de dezembro de 1991. Restabelece princípios da Lei ${ }^{\circ} 7.505$, de 2 de julho de 1986, institui o Programa Nacional de Apoio à Cultura (Pronac) e dá outras providências. Disponível em <http://www.planalto.gov.br/ccivil_03/leis/L8313cons.htm>. Acesso em: 05.06.2016.

Lei n. ${ }^{\circ}$ 8.389, de 30 de dezembro de 1991. Institui o Conselho de Comunicação Social, na forma do art. 224 da Constituição Federal e dá outras providências. Disponível em <http://www.planalto.gov.br/ccivil_03/leis/18389.htm>. Acesso em: 05.06.2016.

Lei n. ${ }^{\circ}$ 9.472, de 16 de julho de 1997. Dispõe sobre a organização dos serviços de telecomunicações, a criação e funcionamento de um órgão regulador e outros aspectos institucionais, nos termos da Emenda Constitucional $\mathrm{n}^{\circ}$ 8, de 1995. Disponível em <http://www.planalto.gov.br/ccivil_03/leis/L9472.htm>. Acesso em: 05.06.2016. 
Lei n. 12.965, de 23 de abril de 2014. Estabelece princípios, garantias, direitos e deveres para o uso da Internet no Brasil. Disponível em <http://www.planalto.gov.br/ccivil_03/_ato2011-2014/2014/lei/112965.htm>. Acesso em: 05.06.2016. Ministério da Cultura. Estruturação, Institucionalização e Implementação do

Sistema Nacional de Cultura. Dez/2011. Disponível em
<http://www.cultura.gov.br/documents/10907/963783/livro11-602-para-aprovacao.pdf/d17c52f93a60-4196-af5c-a6655f028f3b>. Acesso em 07.05.2016.

Presidência da República. Secretaria de Comunicação Social. Pesquisa brasileira de mídia 2015: hábitos de consumo de mídia pela população brasileira. Brasília : Secom, 2014. Disponível em $\quad$ file:///C:/Users/Carol/Downloads/Pesquisa\%20Brasileira\%20de\%20M\%C3\%ADdia\%20\%20PBM\%202015.pdf>. Acesso em 07.08.2016.

DÍAZ BORDENAVE, Juan E. O que é comunicação. São Paulo: Brasiliense, 2006 (Coleção primeiros passos).

FIORILLO, Celso Antonio Pacheco. Curso de Direito Ambiental Brasileiro. São Paulo: Saraiva, 2014.

Princípios constitucionais do direito da sociedade da informação: a tutela jurídica do meio ambiente digital. São Paulo: Saraiva, 2015.

Meio Ambiente Cultural e Internet: O Potencial das Tecnologias da Comunicação para a Sustentabilidade na Sociedade da Informação. Revista Brasileira de Direito Ambiental, São Paulo, v. 23, p. 73-97, jul./set., 2010.

\section{FÓRUM NACIONAL PELA DEMOCRATIZAÇÃO DA COMUNICAÇÃO. Indicação do} Conselho de Comunicação Social é retrógrada e antidemocrática. Nota Oficial. 19.07.2012. Disponível em <http://www.fndc.org.br/noticias/indicacao-do-conselho-de-comunicacao-social-eretrograda-e-antidemocratica-809985/>. Acesso em 28.08.2016.

INSTITUTO PAULO MONTENEGRO; AÇÃO EDUCATIVA. Indicador de Alfabetismo Funcional - INAF: estudo especial sobre alfabetismo e mundo do trabalho. Disponível em: < 
file://CC:/Users/Carol/Downloads/INAFEstudosEspeciais_2016_Letramento_e_Mundo_do_Trabalho.p df>. Acesso em 10.07.2016.

INTERVOZES. Direito à comunicação. [200-?] Disponível em <http://www.intervozes.org.br/direitoacomunicacao/?page_id=28545>. Acesso em 10.06.2016.

JAMBEIRO, Othon. Regulando a TV: uma visão comparativa no Mercosul. Salvador: EDUFBA, 2000.

A TV no Brasil do século XX. Salvador: EDUFBA, 2001.

MELO, Karine. Conselho de Comunicação Social toma posse em meio a críticas. 15.07.2015. Disponível em <http://agenciabrasil.ebc.com.br/politica/noticia/2015-07/conselho-decomunicacao-social-toma-posse-em-meio-criticas>. Acesso em 22.06.2016.

\section{ORGANIZAÇÃO DAS NAÇÕES UNIDAS (ONU). Declaração Universal dos Direitos} Humanos. Janeiro/2009. Disponível em $\quad<$ http://www.dudh.org.br/wpcontent/uploads/2014/12/dudh.pdf>. Acesso em 05.09.2016.

PROGRAMA DAS NAÇÕES UNIDAS PARA O DESENVOLVIMENTO (PNUD). Relatório do Desenvolvimento Humano 2015. Disponível em <file:///C:/Users/Carol/Downloads/undp-br-hdr_ptBR-2015.pdf>. Acesso em 07.08.2016.

UNESCO. Um mundo, muitas vozes (Relatório MacBride). Rio de Janeiro: FGV, 1983. 